\title{
Microstructure and Superconductivity of Bi/Ni bilayers Prepared by Pulsed Laser Deposition
}

\author{
L.Y. Liu ${ }^{1}$, Y. T. Xing ${ }^{2}$, D. F. Franceschini ${ }^{2}$ and I. G. Solórzano ${ }^{1}$ \\ 1. DEQM, Pontifícia Universidade Católica do Rio de Janeiro, Rio de Janeiro, Brasil \\ ${ }^{2 .}$ Instituto de Física, Universidade Federal Fluminense, Niterói, Brasil
}

In spite of crystalline bismuth (rhombohedra structure) and nickel (Face Centered Cubic structure) are not superconducting, $\mathrm{Bi} / \mathrm{Ni}$ bi-layers show a superconducting transition at $\sim 4 \mathrm{~K}$ and this has been attracted grate attention [1]. There are different interpretations of the superconductivity in $\mathrm{Bi} / \mathrm{Ni}: \mathrm{Ni}$ induced FCC $\mathrm{Bi}$ [2]; magnetic fluctuation at the interface of $\mathrm{Ni} / \mathrm{Bi}$ induced superconductivity [3]; formation of $\mathrm{NiBi}_{3}$ at the interface [4], $\mathrm{Bi}$ induced superconductivity in $\mathrm{Ni}$ layer and formation of a very thin amorphous $\mathrm{Bi}$ layer formed at the interface of $\mathrm{Ni}$ and $\mathrm{Bi}$ [5], etc. In this work we study the superconductivity and microstructure of the $\mathrm{Bi} / \mathrm{Ni}$ bilayer by means of transport and high resolution transmission electron microscopy (HRTEM), in order to find out what induced the superconductivity in $\mathrm{Bi} / \mathrm{Ni}$ bilayer system. The thickness of the first deposited Bi layer is fixed as $38 \mathrm{~nm}$ and the followed deposited $\mathrm{Ni}$ layer changes from $2 \mathrm{~nm}$ to $\sim 40 \mathrm{~nm}$. The transport measurements exhibits superconductivity as expected (as shown in Fig. 1) and the critical superconducting transition temperature $\left(\mathrm{T}_{\mathrm{c}}\right)$ is $\sim 4 \mathrm{~K}$, which is in agreement with the results in the literatures. The cross-section samples for TEM study have been prepared by FIB and when the deposited Ni layer is less than $8 \mathrm{~nm}$, pure Ni layer cannot be seen in the sample (Fig. 2). It indicates that the $\mathrm{Ni}$ atoms diffused into the $\mathrm{Bi}$ layer during deposition.

When increase the thickness of the Ni layer, however, three continuous layers can be clearly seen in the cross-section sample. HRTEM imaging shows that the middle layer is the intermetallic superconducting phase $\mathrm{NiBi}_{3}$ (Fig. 3). The $\mathrm{NiBi}_{3}$ layer could be formed during the pulsed laser deposition (PLD) or the preparation by FIB. A Bi/Ni sample have been prepared by thermo-evaporation at $4.2 \mathrm{~K}$ (as shown in Fig. 4) and studied by the same methods to see in which stage the $\mathrm{NiBi}_{3}$ has been formed. The transport studies show that after annealing at $300 \mathrm{~K}$, the low-temperature prepared sample does not show superconductivity and the cross-section structure is pure $\mathrm{Bi}$ and $\mathrm{Ni}$ layers. This confirmed that the $\mathrm{NiBi}_{3}$ layer observed in the PLD prepared samples has been formed during the deposition and sample preparation for TEM with FIB does not induce the reaction of $\mathrm{Bi}$ and $\mathrm{Ni}$. In summary, we observed a clearly $\mathrm{NiBi}_{3}$ layer between the deposited $\mathrm{Bi}$ and $\mathrm{Ni}$ layers and this layer is the origin of the superconductivity in $\mathrm{Bi} / \mathrm{Ni}$ systems prepared by PLD. The diffusion of $\mathrm{Ni}$ atoms into Bi layers and formation of $\mathrm{NiBi}_{3}$ occurred during the deposition and TEM sample preparation by FIB cannot induce this reaction [6].

\section{References :}

[1] Kurti, N., Simon, F. E. Proc. R. Soc. London, Ser. A 151 (1935), p. 610.

[2] LeClair, P. et al, Phys. Rev. Lett. 94 (2005), 037006.

[3] X. X. Gong et al, Chin. Phys. Lett. 32 (2015), 067402.

[4] Siva et al, J. Appl. Phys. 117 (2015), 083902.

[5] Weitzel, B., Micklitz, H., Phys. ReV. Lett. 66 (1991), p. 385.

[6] This research has been sponsored by CNPq and CAPES (Brazil). The access to the facilities for electron microscopy at in the LabNano/CBPF and LMES/UFF, is gratefully acknowledged. 


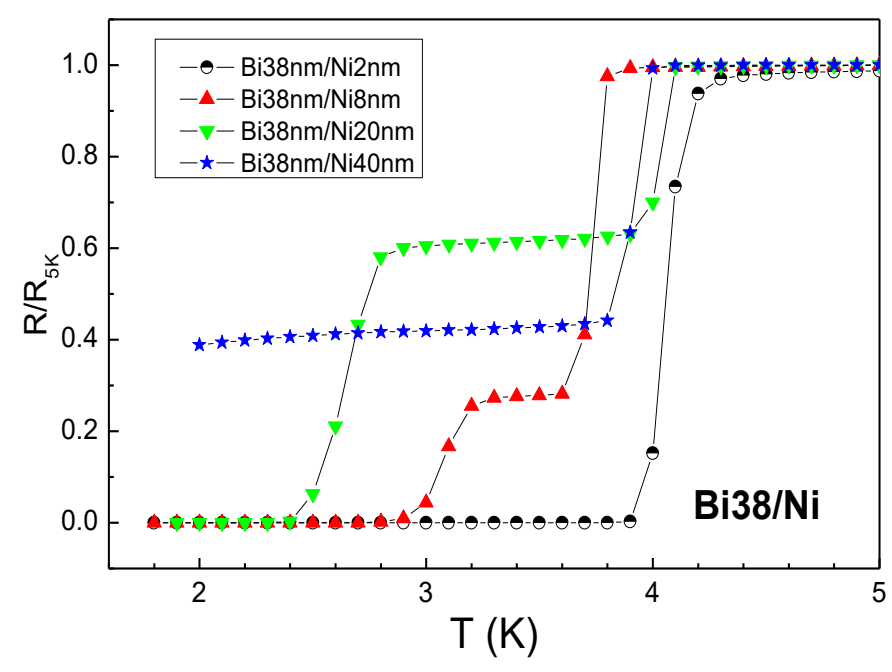

Figure 1. Normalized resistivity as a function of temperature for samples with fixed thickness of $\mathrm{Bi}$ and different thickness of Ni layers.

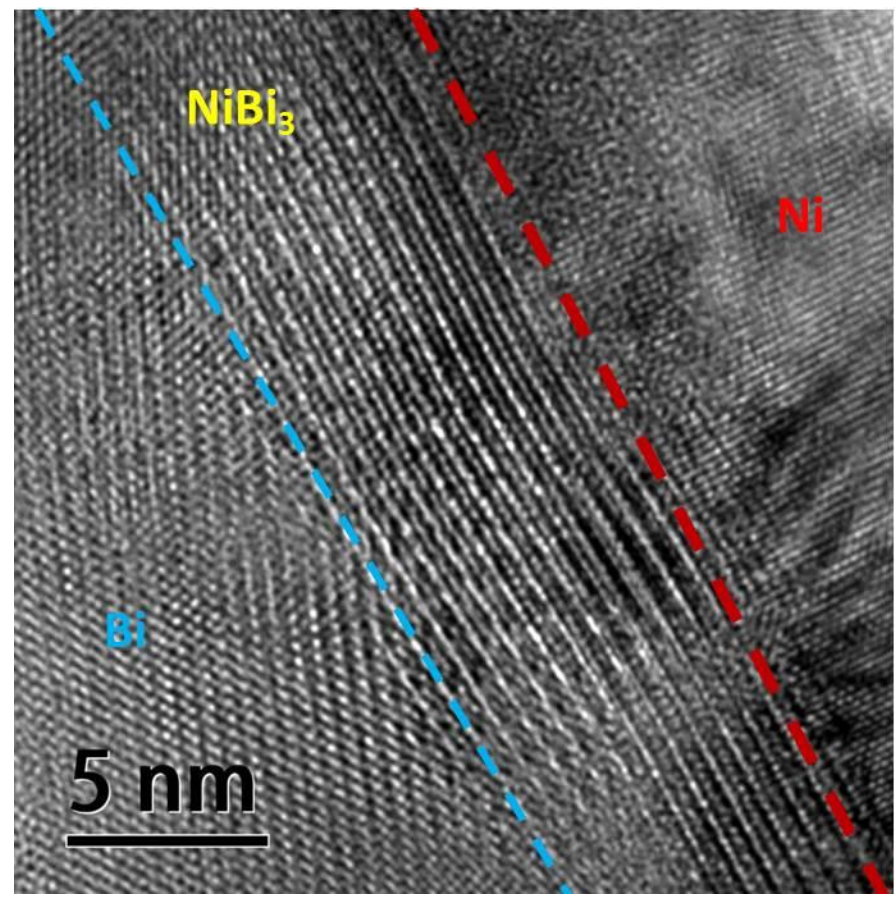

Figure 3. HRTEM image of cross-section of sample Bi38nm/Ni20nm prepared by PLD.

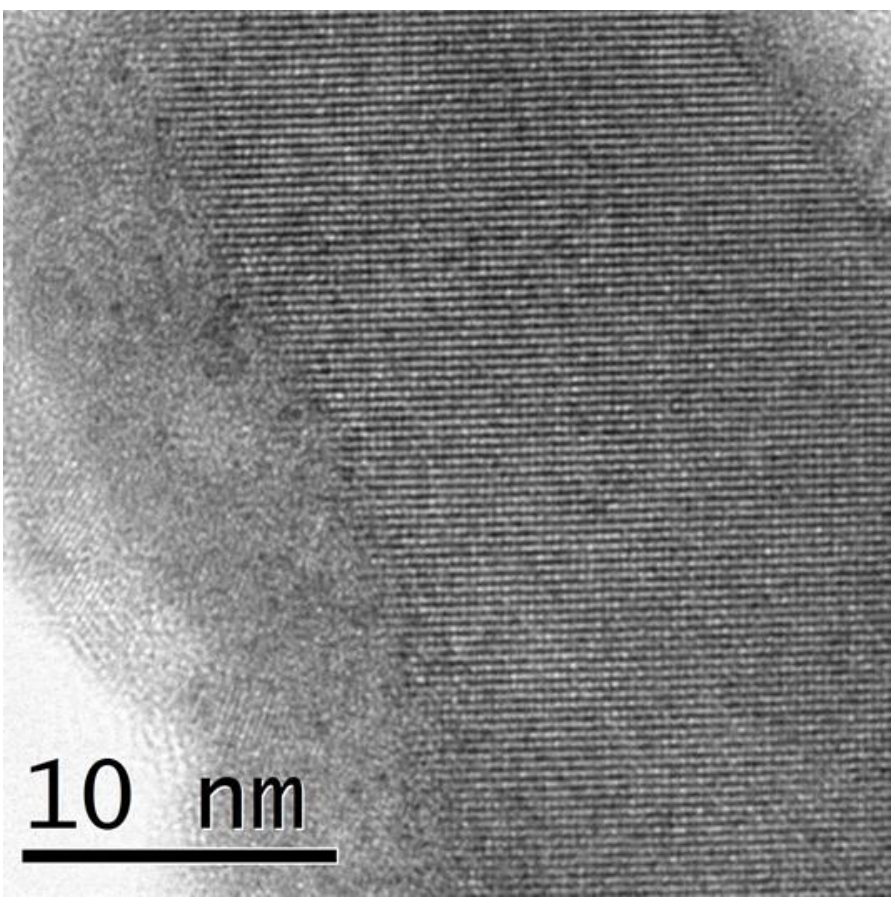

Figure 2. HRTEM image of cross-section of sample Bi38nm/Ni8nm prepared by PLD.

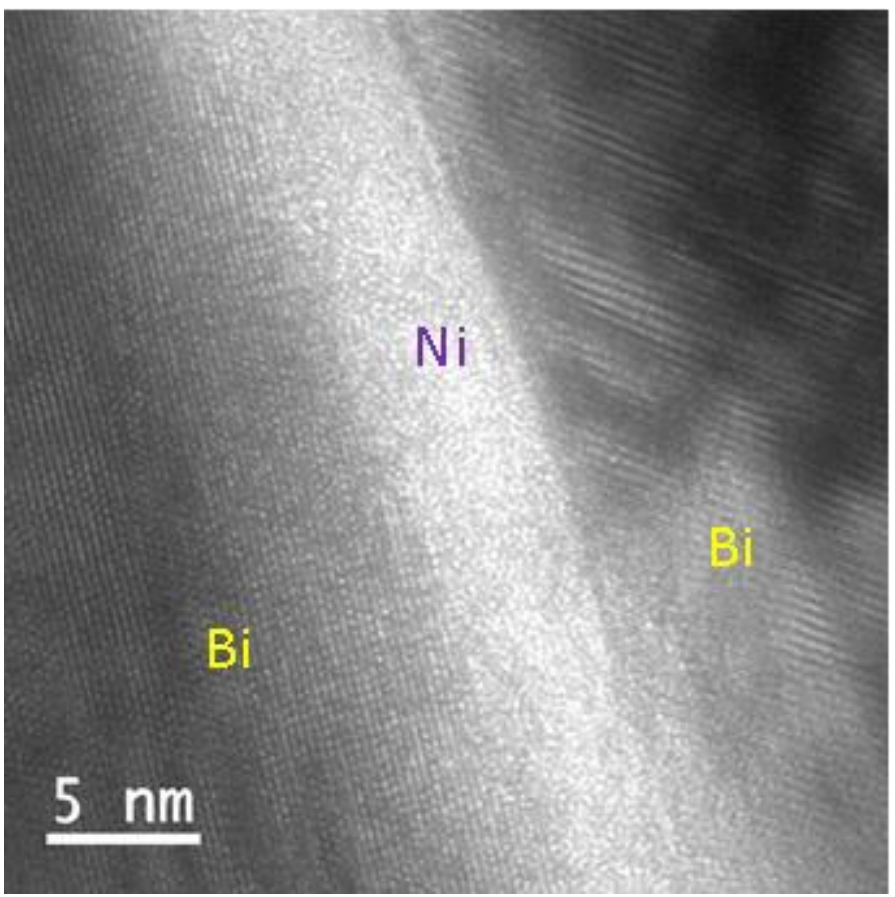

Figure 4. HRTEM image of cross-section of $\mathrm{Bi}-\mathrm{Ni}-\mathrm{Bi}$ layers prepared at $4.2 \mathrm{~K}$. 